Pacific Journal of Mathematic 


\title{
DOUBLE BRANCHED COVERS AND PRETZEL KNOTS
}

\author{
RICHARD E. BEDIENT
}

\begin{abstract}
Given a knot $K$ we describe a modification of $K$ which leaves the double branched cover of $S^{3}$ branched along $K$ unchanged. We then modify certain pretzel knots in this way to produce arbitrarily large families of distinct knots having the property that all of the associated double branched covers are homeomorphic.
\end{abstract}

1. Introduction. This paper concerns the relationship between a knot and its associated double branched cover. A brief review of the history of this problem will indicate some of the known results.

Given a tame knot $K$ in $S^{3}$ the unique representation of $\Pi_{1}\left(S^{3}-K\right)$ onto $Z_{2}$ yields a unique closed orientable 3-manifold $M(K)$ called the double branched cover of $S^{3}$ branched along $K$. By Waldhausen [17] $K$ is trivial if and only if $M(K) \approx S^{3}$. This leads one to ask whether knot types and the homeomorphism types of their branched covers are in one-to-one correspondence. Birman and Hilden [2] give an affirmative answer in the case where the Heegaard genus of $M(K)$ is 2 and where homeomorphism type is replaced by Heegaard splitting class.

Unfortunately (or possibly fortunately) when the above restriction on genus is removed, counter-examples appear in abundance. Montesinos [8] and Viro [16] independently give examples of distinct composite links for which the double covers are homeomorphic. Birman, Gonzalez-Acuna and Montesinos [3] remove the restrictions "composite" and "link" by producing pairs of distinct prime knots such that for each pair the double covers are the same. These examples are also described in different ways by Takahashi [14] and Bedient [1]. Montesinos [7] has also given examples of arbitrarily large families of distinct links such that within each family all of the associated double covers are homeomorphic.

In this paper we will show that such families of knots exist. Boileau and Siebenmann [4] have obtained similar examples.

This result can be interpreted in a different manner as follows. We note that the manifold constructed is a Seifert fibered manifold which then admits $n$ distinct involutions where distinct here means non-conjugate in the automorphism group. For more on this see Plotnick [11]. 
2. The modification. As a first step in the construction we exhibit a modification discussed in detail by Montesinos which may be made on any suitable knot (or link) which will not change the homeomorphism type of the associated double branched cover. It may or may not change the knot type.

Suppose that a knot $K$ contains a section like the one shown in Figure 1 where $A$ and $B$ represent "rational tangles" as described by Conway [5]. If $A$ and $B$ are interchanged the resulting knot $K^{\prime}$ is shown in Figure 2. Montesinos [7] shows that $M(K) \approx M\left(K^{\prime}\right)$.

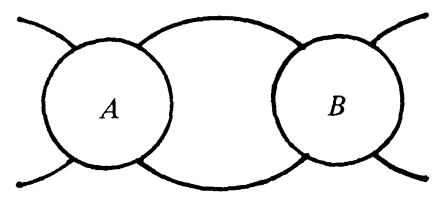

FIGURE 1

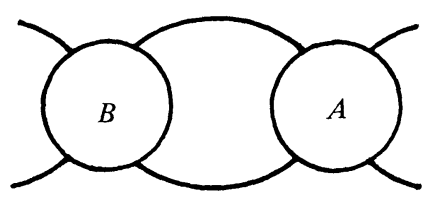

FIGURE 2

3. Pretzel knots. We now extend the technique to construct the examples promised in the introduction. We start with a generalization of the well-known pretzel knots.

We will denote the knot in Figure 3 by $K\left(p_{1}, \ldots, p_{n}\right)$ where the $p_{\imath} \in Z$ represent the number of half twists.

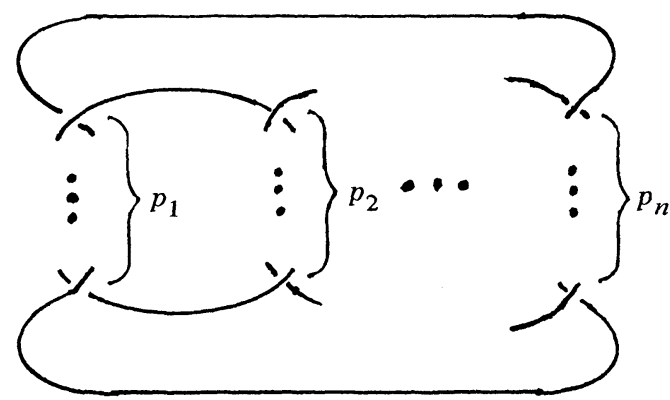

Figure 3

REMARK. If more than one of the $p_{l}$ is even or if $n$ is even and none of the $p_{i}$ is even then $K$ is a link. In all other cases however $K$ is a knot. This does not affect the results which follow. 
To construct the double branched cover of $K$, we apply the techniques of Montesinos [6] and [7], removing and replacing the balls $B_{1}, B_{2}, \ldots, B_{n+1}$ as shown in Figure 4 . Note the special role played by the ball $B_{n+1}$. Let $\varphi$ be any permutation of the numbers $1,2, \ldots, n$. Then by the previous discussion,

$$
M\left(K\left(p_{1}, \ldots, p_{n}\right)\right) \approx M\left(K\left(p_{\varphi(1)}, \ldots, p_{\varphi(n)}\right)\right)
$$

since we may interchange the first $n$ balls at will. It is also clear that if $\varphi$ is a cyclic permutation of $1,2, \ldots, n$ or if $\varphi$ simply reverses the order of $1,2, \ldots, n$ or is any combination of these, then

$$
K\left(p_{1}, \ldots, p_{n}\right) \sim K\left(p_{\varphi(1)}, \ldots, p_{\varphi(n)}\right) .
$$
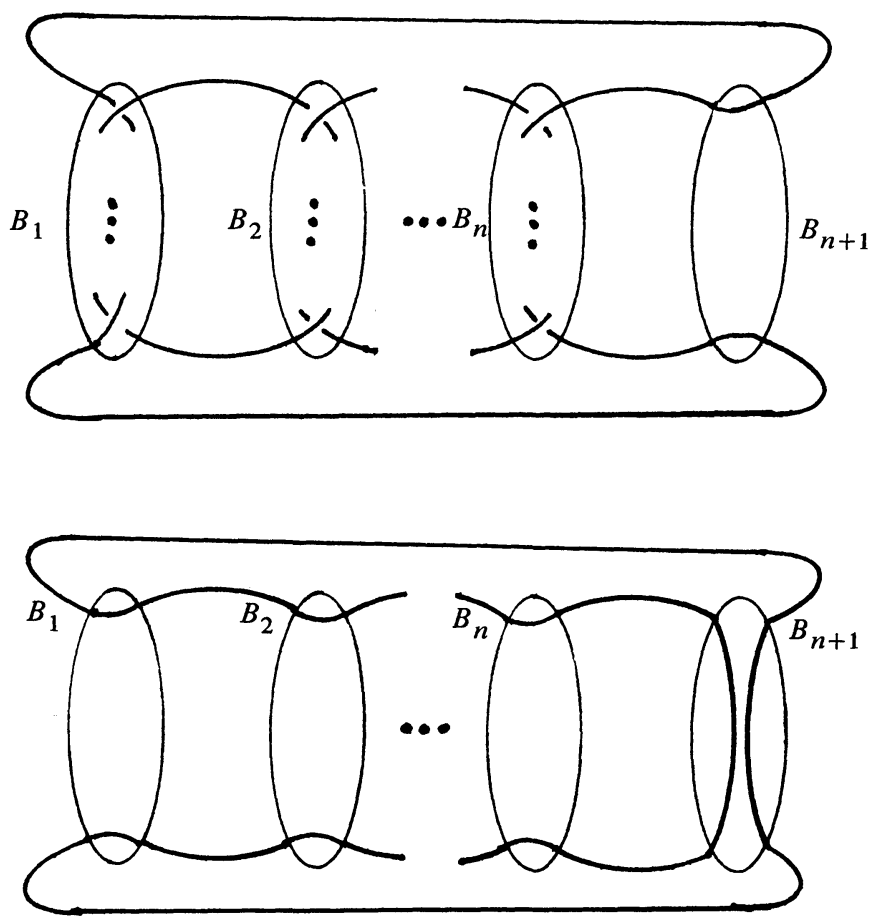

FIGURE 4

The above conditions turn out to be sufficient. We state this as the following theorem:

TheOREM. Let $p_{i}>1 \in Z$ such that the $p_{i}$ are distinct, $i=1, \ldots, n$, and such that $\Sigma 1 / p_{i}<1$. Let $K\left(p_{1}, \ldots, p_{n}\right)$ be as in Figure 6. Then

$$
M\left(K\left(p_{1}, \ldots, p_{n}\right)\right) \approx M\left(K\left(p_{\varphi(1)}, \ldots, p_{\varphi(n)}\right)\right)
$$


for any permutation $\varphi$ of $1, \ldots, n$. However,

$$
K\left(p_{1}, \ldots, p_{n}\right) \sim K\left(p_{\varphi(1)}, \ldots, p_{\varphi(n)}\right)
$$

if and only if $\varphi$ is a cyclic permutation, an order reversing permutation or a combination of these.

Before proceeding to the proof of the theorem, we will state and prove the following corollary.

COROLLARY. There exist arbitrarily large families of distinct knots with homeomorphic double branched covers.

Proof of Corollary. For any given $n$ there are $n$ ! distinct permutations of $1, \ldots, n$ and only $2 n$ permutations which satisfy the conditions of the theorem. Thus, there are $n ! / 2 n=(n-1) ! / 2$ distinct pretzel knots for each choice of $n$.

Proof of Theorem. The first part of the theorem is clear from the discussion preceding the statement of the theorem. Thus we must show the equivalence of the conditions on the permutation $\varphi$ and the isotopy between $K\left(p_{1}, \ldots, p_{n}\right)$ and $K\left(p_{\varphi(1)}, \ldots, p_{\varphi(n)}\right)$. We start with a method first used by Riedemeister [12]. Let $\Pi=\Pi_{1}\left(S^{3}-K\left(p_{1}, \ldots, p_{n}\right)\right)$. Next let $H$ be the normal closure in $\Pi$ of the square of any meridian (and hence all meridians). Form $G=\Pi / H$. Now let $F=[G, G]$ the commutator subgroup of $G$. Let $U$ be the center of $F$ and form $W=G / U$. Make this same construction for $K^{\prime}=K\left(p_{\varphi(1)}, \ldots, p_{\varphi(n)}\right)$ to form $\Pi^{\prime}, G^{\prime}$, and $W^{\prime}$. We want to show the relationship between the properties of $\varphi$ and those of $K$ and $K^{\prime}$. This will be done in two steps, denoted Lemmas 1 and 2.

LEMMA 1. If $K \sim K^{\prime}$ then $W \approx W^{\prime}$.

LEMMA 2. $W \approx W^{\prime}$ if and only if $\varphi$ has the properties noted in the theorem.

Proof of Lemma 1. If $K \sim K^{\prime}$ then there exists an isotopy of the pair $\left(S^{3}, K\right)$ to the pair $\left(S^{3}, K^{\prime}\right)$ which will induce an isomorphism from $\Pi$ to $\Pi^{\prime}$. We will see in what follows that the generators used to describe $\Pi$ (respectively $\Pi^{\prime}$ ) are meridians. Geometrically these are curves which are null-homotopic in a tubular neighborhood of $K\left(K^{\prime}\right)$. All such curves represent conjugate elements of $\Pi\left(\Pi^{\prime}\right)$. Thus the elements whose squares generate $H$ must map to the elements whose squares generate $H^{\prime}$. It then follows that $G \approx G^{\prime}$. 
The commutator subgroup $F$ of $G$ and its center $U$ must be carried to $F^{\prime}$ and $U^{\prime}$ respectively by any isomorphism of $G$ to $G^{\prime}$. Hence we have induced an isomorphism from $W$ to $W^{\prime}$.

Proof of Lemma 2. We will compute nice presentations for $W$ and $W^{\prime}$ and then show that they are recognizable as groups of isometries of the hyperbolic plane. Here we are following Trotter [15].

We start by finding $\Pi=\Pi_{1}\left(S^{3}-K\left(p_{1}, \ldots, p_{n}\right)\right)$. We will use the Wertinger generators shown in Figure 5 . Let $m_{i}$ be defined by $p_{i}=$ $2 m_{i}+1, i=1, \ldots, n$. Each two stranded braid in Figure 5 can be used to write the generators $x_{l}^{\prime}$ in terms of the generators $x_{i}$ and also to eliminate all other generators as follows: $\Pi$ is generated by $x_{1}, \ldots, x_{n}$, $x_{1}^{\prime}, \ldots, x_{n}^{\prime}$ with relations

$$
\begin{aligned}
& x_{1}^{\prime}=\left(x_{n} x_{1}^{-1}\right)^{m_{n}} x_{n}\left(x_{1} x_{2}^{-1}\right)^{-m_{n}} \\
& x_{1}^{\prime}=\left(x_{1} x_{2}^{-1}\right)^{m_{1}+1} x_{2}\left(x_{1} x_{2}^{-1}\right)^{-m_{1}-1} \\
& x_{2}^{\prime}=\left(x_{1} x_{2}^{-1}\right)^{m_{1}} x_{1}\left(x_{1} x_{2}^{-1}\right)^{-m_{1}} \\
& x_{2}^{\prime}=\left(x_{2} x_{3}^{-1}\right)^{m_{2}+1} x_{3}\left(x_{2} x_{3}^{-1}\right)^{-m_{2}-1}
\end{aligned}
$$

and similar pairs for $x_{3}^{\prime}, \ldots, x_{n}^{\prime}$. We may use these to eliminate the $x_{i}^{\prime}$ so that $\Pi$ is now generated by $x_{1}, \ldots, x_{n}$ with $n$ relations of the form

$$
\left(x_{n} x_{1}^{-1}\right)^{m_{n}} x_{n}\left(x_{n} x_{1}^{-1}\right)^{-m_{n}}=\left(x_{1} x_{2}^{-1}\right)^{m_{1}+1} x_{2}\left(x_{1} x_{2}^{-1}\right)^{-m_{1}-1} .
$$

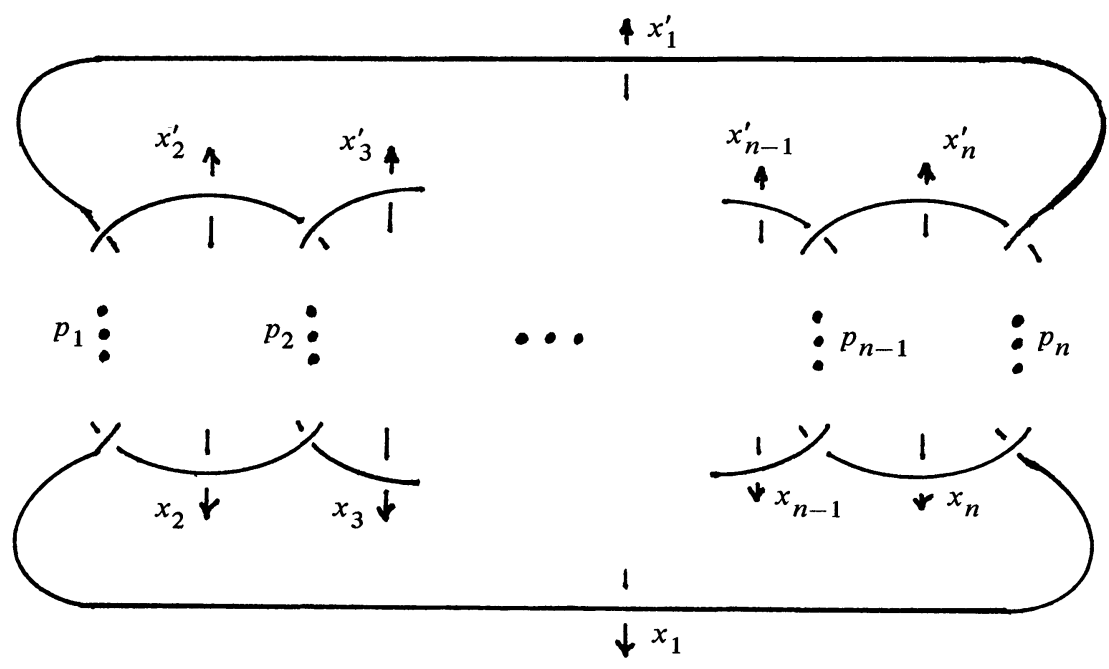

FIGURE 5 
Recall that $H$ is the normal subgroup of $\Pi$ generated by the squares of the $x_{i}$. To form $\Pi / H$ we just add the relations $x_{i}^{2}=1, i=1,2, \ldots, n$ to those of $\Pi$. Replacing $x_{i}^{-1}$ by $x_{i}$ and simplifying, the above relation becomes

$$
\left(x_{n} x_{1}\right)^{p_{n}}=\left(x_{1} x_{2}\right)^{p_{1}} .
$$

We do this for each of the remaining relations to get

$$
\begin{aligned}
\Pi / H=G=\left\{x_{1}, \ldots, x_{n} \mid\left(x_{1} x_{2}\right)^{p_{1}}=\left(x_{2} x_{3}\right)^{p_{2}}\right. & =\cdots=\left(x_{n} x_{1}\right)^{p_{n}}, \\
x_{1}^{2} & \left.=x_{2}^{2}=\cdots=x_{n}^{2}=1\right\} .
\end{aligned}
$$

Algebraic manipulations show that the commutator subgroup $F$ of $G$ is generated by $\left(x_{1} x_{2}\right),\left(x_{2} x_{3}\right), \ldots,\left(x_{n} x_{1}\right)$. Thus

$$
\begin{aligned}
F=\left\{\left(x_{1} x_{2}\right), \ldots,\left(x_{n} x_{1}\right) \mid\left(x_{1} x_{2}\right)^{p_{1}}=\left(x_{2} x_{3}\right)^{p_{2}}\right. & =\cdots=\left(x_{n} x_{1}\right)^{p_{n}}, \\
x_{1}^{2} & \left.=x_{2}^{2}=\cdots=x_{n}^{2}=1\right\} .
\end{aligned}
$$

The next step is to show that the subgroup $U$ of $F$ generated by $\left(x_{1} x_{2}\right)^{p_{1}}$ is the center of $F$. The fact that $U$ is contained in the center of $F$ follows from the relations in $F$. To show that $U$ is in fact the entire center of $F$ we show that $F / U$ is centerless. First note that

$$
\begin{aligned}
F / U=\left\{\left(x_{1} x_{2}\right), \ldots,\left(x_{n} x_{1}\right) \mid\left(x_{1} x_{2}\right)^{p_{1}}=\right. & \left(x_{2} x_{3}\right)^{p_{2}}=\cdots=\left(x_{n} x_{1}\right)^{p_{n}} \\
& \left.=x_{1}^{2}=x_{2}^{2}=\cdots=x_{n}^{2}=1\right\} .
\end{aligned}
$$

This however, is isomorphic to the group denoted by $Q /\langle h\rangle$ and shown to be centerless by Raymond and Orlik [9]. Finally we have

$$
\begin{aligned}
W=G / U=\left\{x_{1}, \ldots, x_{n} \mid\left(x_{1} x_{2}\right)^{p_{1}}=\left(x_{2} x_{3}\right)^{p_{2}}\right. & =\cdots=\left(x_{n} x_{1}\right)^{p_{n}} \\
& \left.=x_{1}^{2}=x_{2}^{2}=\cdots=x_{n}^{2}=1\right\} .
\end{aligned}
$$

Now consider a permutation $\varphi$ of $1, \ldots, n$ and construct $\Pi^{\prime}=$ $\Pi_{1}\left(S^{3}-K\left(p_{\varphi(1)}, \ldots, p_{\varphi(n)}\right)\right)$. We follow exactly the same procedure as above to get

$$
\begin{aligned}
W^{\prime}=\left\{x_{1}, \ldots, x_{n} \mid\left(x_{1} x_{2}\right)^{p_{\varphi(1)}}=\left(x_{2} x_{3}\right)^{p_{\varphi(2)}}\right. & =\cdots=\left(x_{n} x_{1}\right)^{p_{\varphi(n)}} \\
& \left.=x_{1}^{2}=x_{2}^{2}=\cdots=x_{n}^{2}=1\right\} .
\end{aligned}
$$

We then need to prove $W \nsim W^{\prime}$ except for the special classes of permutations allowed in the theorem. Still following Trotter we construct an $n$-gon $P$ in the hyperbolic plane with vertex angles $\pi / p_{1}, \pi / p_{2}, \ldots, \pi / p_{n}$ as in Figure 6. Let $y_{l}$ be reflection in the lines shown in Figure 6. Note that 
$\left(y_{l} y_{l+1}\right)$ is rotation through an angle $2 \pi / p_{t}$ about the vertex with angle $\pi / p_{l}$. Thus, the map $x_{l} \rightarrow y_{l}$ induces an isomorphism of $W$ to the full group of isometries of the plane with fundamental region $P$. Referring to Macbeath [8] we find that these are exactly the non-Euclidean crystallographic (NEC) groups which he classifies in Theorems 1 and 1a. Using his notation

$$
W=\left(0,+,[],\left\{\left(p_{1}, \ldots, p_{n}\right)\right\}\right)
$$

and

$$
W^{\prime}=\left(0,+,[],\left\{\left(p_{\varphi(1)}, \ldots, p_{\varphi(n)}\right)\right\}\right) .
$$

Then by the theorems just mentioned $W \approx W^{\prime}$ if and only if $\varphi$ is a cyclic permutation, an order reversing permutation, or a combination of these. $\square$

This together with Lemma 1 concludes the proof of the theorem.

It seems clear from the nature of the construction as well as from the work of Montesinos that this phenomenon is fairly common. That is, if the balls which are being permuted are more complicated than those in the pretzel knots the same results would be expected.

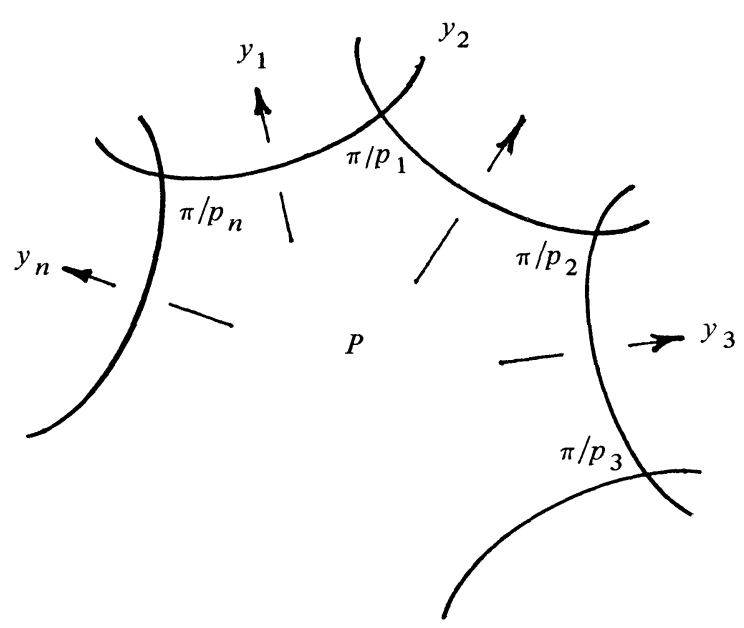




\section{REFERENCES}

[1] R. E. Bedient, Surgery Presentations and Double Branched Covers, Thesis: The University of Michigan, 1980.

[2] J. S. Birman, and H. M. Hilden, Heegaard splittings of branched coverings of $S^{3}$, Trans. Amer. Math. Assoc., 213 (1975).

[3] J. S. Birman, F. Gonzalez-Acuna, and J. M. Montesinos, Heegaard splittings of prime 3-manifolds are not unique, Michigan Math. J., 23 (1976).

[4] M. Boileau, and L. Siebenmann, A planar classification of Pretzel knots and Montesinos knots, to appear.

[5] J. H. Conway, An Enumeration of Knots and Links and Some of Their Algebraic Properties, Computational Problems in Abstract Algebra, (London: Pergamon Press, 1970).

[6] A. M. Macbeath, Clalssification of non-Euclidean plane crystallographic groups, Canad. J. Math., 6 (1976).

[7] J. Montesinos, Revetements Ramifies de Noeuds, Espaces Fibres de Seifert et Scindements de Heegaard, to appear in Asterisque.

[8] _ Sobre la Conjectura de Poincare y los Recubridores Ramificados Sobre Un Nudo, Tesis: Facultad de Ciencias, Universidad Complutense de Madrid, 1972.

[9] _ Surgery on Links and Double Branched Covers of $S^{3}$, Papers Dedicated to R. H. Fox, ed. L. Neuwirth, (Princeton: Princeton University Press, 1975).

[10] P. Orlik, and F. Raymond, Actions of SO(2) on 3-Manifolds, Proc. Conference on Transformation Groups, New Orleans 1967, (New York: Springer-Verlag, 1968).

[11] S. P. Plotnick, Knots, Automorphisms and Homology 4-Spheres, Thesis: The University of Michigan, 1979.

[12] K. Reidemeister, Knotentheorie, Ergebn. Math., 1 (1932).

[13] D. Rolfsen, Knots and Links, (Boston: Publish or Perish Inc., 1976).

[14] M. Takahashi, Two Knots With The Same 2-Fold Branched Cover, Yokahama Math. J., 25 (1977).

[15] H. F. Trotter, Non-invertible Knots Exist, Topology, 2 (1964).

[16] O. J. Viro, Linkings, 2-sheeted branched coverings and braids, Math. USSR Sbornik, 16 (1972).

[17] F. Waldhausen, Uber Involutionen der 2-Sphare, Topology, 8 (1969).

Received June 4, 1982 and in revised form November 29, 1982.

Hamilton College

Clinton, NY 13323 


\title{
PACIFIC JOURNAL OF MATHEMATICS EDITORS
}

\author{
Donald BabBITT (Managing Editor) \\ University of California \\ Los Angeles, CA 90024 \\ Hugo Rossi \\ University of Utah \\ Salt Lake City, UT 84112 \\ C. C. Moore and Arthur Ogus \\ University of California \\ Berkeley, CA 94720
}

\author{
J. Dugundu \\ Department of Mathematics \\ University of Southern California \\ Los Angeles, CA 90089-1113
}

R. FINN and H. SAMELSON

Stanford University

Stanford, CA 94305

\section{ASSOCIATE EDITORS}
R. ARENS
E. F. BECKENBACH
B. H. NeumanN
F. WolF
K. YosHIDA (1906-1982)

\section{SUPPORTING INSTITUTIONS}

\author{
UNIVERSITY OF ARIZONA \\ UNIVERSITY OF BRITISH COLUMBIA \\ CALIFORNIA INSTITUTE OF TECHNOLOGY \\ UNIVERSITY OF CALIFORNIA \\ MONTANA STATE UNIVERSITY \\ UNIVERSITY OF NEVADA, RENO \\ NEW MEXICO STATE UNIVERSITY \\ OREGON STATE UNIVERSITY
}

\author{
UNIVERSITY OF OREGON \\ UNIVERSITY OF SOUTHERN CALIFORNIA \\ STANFORD UNIVERSITY \\ UNIVERSITY OF HAWAII \\ UNIVERSITY OF TOKYO \\ UNIVERSITY OF UTAH \\ WASHINGTON STATE UNIVERSITY \\ UNIVERSITY OF WASHINGTON
}

The Supporting Institutions listed above contribute to the cost of publication of this Journal, but they are not owners or publishers and have no responsibility for its content or policies.

Mathematical papers intended for publication in the Pacific Journal of Mathematics should be in typed form or offset-reproduced (not dittoed), double spaced with large margins. Please do not use built up fractions in the text of the manuscript. However, you may use them in the displayed equations. Underline Greek letters in red, German in green, and script in blue. The first paragraph must be capable of being used separately as a synopsis of the entire paper. In particular it should contain no bibliographic references. Please propose a heading for the odd numbered pages of less than 35 characters. Manuscripts, in triplicate, may be sent to any one of the editors. Please classify according to the scheme of Math. Reviews, Index to Vol. 39. Supply name and address of author to whom proofs should be sent. All other communications should be addressed to the managing editor, or Elaine Barth, University of California, Los Angeles, California 90024.

There are page-charges associated with articles appearing in the Pacific Journal of Mathematics. These charges are expected to be paid by the author's University, Government Agency or Company. If the author or authors do not have access to such Institutional support these charges are waived. Single authors will receive 50 free reprints; joint authors will receive a total of 100 free reprints. Additional copies may be obtained at cost in multiples of 50 .

The Pacific Journal of Mathematics is issued monthly as of January 1966. Regular subscription rate: $\$ 132.00$ a year (6 Vol., 12 issues). Special rate: $\$ 66.00$ a year to individual members of supporting institutions.

Subscriptions, orders for numbers issued in the last three calendar years, and changes of address should be sent to Pacific Journal of Mathematics, P.O. Box 969, Carmel Valley, CA 93924, U.S.A. Old back numbers obtainable from Kraus Periodicals Co., Route 100, Millwood, NY 10546.

The Pacific Journal of Mathematics ISSN 0030-8730 is published monthly by the Pacific Journal of Mathematics at P.O. Box 969, Carmel Valley, CA 93924. Application to mail at Second-class postage rates is pending at Carmel Valley, California, and additional mailing offices. Postmaster: Send address changes to Pacific Journal of Mathematics, P. O. Box 969, Carmel Valley, CA 93924.

PUBLISHED BY PACIFIC JOURNAL OF MATHEMATICS. A NON-PROFIT CORPORATION

Copyright $\odot 1984$ by Pacific Journal of Mathematics 


\section{Pacific Journal of Mathematics}

\section{Vol. 112, No. $2 \quad$ February, 1984}

Kenneth F. Andersen and Wo-Sang Young, On the reverse weak type inequality for the Hardy maximal function and the weighted classes

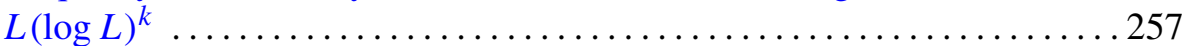

Richard Eugene Bedient, Double branched covers and pretzel knots ..... 265

Harold Philip Boas, Holomorphic reproducing kernels in Reinhardt

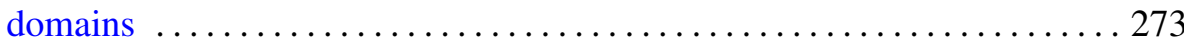

Janey Antonio Daccach and Arthur Gabriel Wasserman, Stiefel's theorem and toral actions ................................. 293

Michael Fried, The nonregular analogue of Tchebotarev's theorem ....... 303

Stanley Joseph Gurak, Minimal polynomials for circular numbers . . . . . . 313

Norimichi Hirano and Wataru Takahashi, Nonlinear ergodic theorems for an amenable semigroup of nonexpansive mappings in a Banach space . . 333

Jim Hoste, Sewn-up $r$-link exteriors . . . . . . . . . . . . . . . . . . . 347

Mohammad Ahmad Khan, The existence of totally dense subgroups in

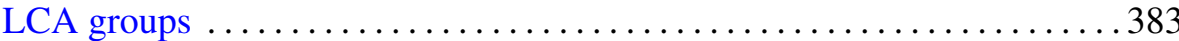

Mieczysław Kula, Murray Angus Marshall and Andrzej Sładek, Direct

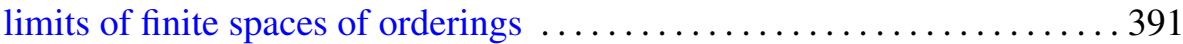

Luis Montejano Peimbert, Flat Hilbert cube manifold pairs ........... 407

Steven C. Pinault, An a priori estimate in the calculus of variations . . . . . 427

McKenzie Y. K. Wang, Some remarks on the calculation of Stiefel-Whitney classes and a paper of Wu-Yi Hsiang's

Brian Donald Wick, The calculation of an invariant for Tor . . 445

Wolfgang Wollny, Contributions to Hilbert's eighteenth problem 